CLINICAL STUDY

\title{
Activating glucokinase (GCK) mutations as a cause of medically responsive congenital hyperinsulinism: prevalence in children and characterisation of a novel GCK mutation
}

\author{
Henrik B T Christesen*, Nicholas D Tribble ${ }^{1, *}$, Anders Molven ${ }^{2,3}$, Juveria Siddiqui ${ }^{1}$, Tone Sandal ${ }^{2,4}$, Klaus Brusgaard $^{5}$, \\ Sian Ellard ${ }^{6}$, Pål R Njølstad ${ }^{4,7}$, Jan Alm ${ }^{8}$, Bendt Brock Jacobsen, Khalid Hussain ${ }^{9}$ and Anna L Gloyn ${ }^{1}$ \\ HC Andersen Children's Hospital, Odense University Hospital, DK-5000 Odense C, Denmark, ${ }^{1}$ Diabetes Research Laboratories, Oxford Centre for Diabetes \\ Endocrinology and Metabolism, University of Oxford, Oxford OX3 7LJ, UK, ${ }^{2}$ The Gade Institute, University of Bergen, N-5021 Bergen, Norway, \\ ${ }^{3}$ Department of Pathology, Haukeland University Hospital, N-5021 Bergen, Norway, ${ }^{4}$ Department of Clinical Medicine, University of Bergen, N-5021 \\ Bergen, Norway, ${ }^{5}$ Department of Clinical Genetics, Odense University Hospital, DK-5000 Odense C, Denmark, ${ }^{6}$ Peninsula Medical School, Institute of \\ Biomedical and Clinical Science, Exeter EX2 5DW, UK, ${ }^{7}$ Department of Pediatrics, Haukeland University Hospital, N-5021 Bergen, Norway, ${ }^{8}$ Department \\ of Paediatrics Karolinska Institute, Karolinska University Hospital, S-171 76 Stockholm, Sweden and ${ }^{9}$ Great Ormond Street Hospital, University College \\ London, London WC1N 3JH, UK
}

(Correspondence should be addressed to A L Gloyn at Diabetes Research Laboratories, Oxford Centre for Diabetes, Endocrinology and Metabolism, Churchill Hospital, Old Road, Headington, Oxford OX3 7LJ, UK; Email: anna.gloyn@drl.ox.ac.uk)

${ }^{*} \mathrm{H}$ B T Christesen and N D Tribble contributed equally to this work

\begin{abstract}
Objective: Activating glucokinase (GCK) mutations are a rarely reported cause of congenital hyperinsulinism (CHI), but the prevalence of GCK mutations is not known.

Methods: From a pooled cohort of 201 non-syndromic children with CHI from three European referral centres (Denmark, $n=141$; Norway, $n=26$; UK, $n=34$ ), 108 children had no $\mathrm{K}_{\mathrm{ATP}}$-channel $(A B C C 8 / K C N J 11)$ gene abnormalities and were screened for GCK mutations. Novel GCK mutations were kinetically characterised.

Results: In five patients, four heterozygous GCK mutations (S64Y, T65I, W99R and A456V) were identified, out of which S64Y was novel. Two of the mutations arose de novo, three were dominantly inherited. All the five patients were medically responsive. In the combined Danish and Norwegian cohort, the prevalence of GCK-CHI was estimated to be $1.2 \%(2 / 167,95 \%$ confidence interval (CI) 0-2.8\%) of all the CHI patients. In the three centre combined cohort of 72 medically responsive children without $\mathrm{K}_{\mathrm{ATP}}$-channel mutations, the prevalence estimate was $6.9 \%(5 / 72,95 \%$ CI $1.1-12.8 \%)$. All activating GCK mutations mapped to the allosteric activator site. The novel S64Y mutation resulted in an increased affinity for the substrate glucose $\left(S_{0.5} 1.49 \pm 0.08\right.$ and $7.39 \pm 0.05 \mathrm{mmol} / \mathrm{l}$ in mutant and wild-type proteins respectively), extrapolating to a relative activity index of $\sim 22$ compared with the wild type.

Conclusion: In the largest study performed to date on GCK in children with CHI, GCK mutations were found only in medically responsive children who were negative for ABCC8 and KCNJ11 mutations. The estimated prevalence $(\sim 7 \%)$ suggests that screening for activating GCK mutations is warranted in those patients.
\end{abstract}

European Journal of Endocrinology 159 27-34

\section{Introduction}

Congenital hyperinsulinism (CHI), also known as hyperinsulinaemic hypoglycaemia or persistent hyperinsulinaemic hypoglycaemia of infancy (PHHI), is a heterogeneous disease entity with disease-causing mutations in at least eight different genes, two major histological types and a highly variable clinical phenotype with respect to the age of onset, duration and severity (1-4). Mutations are most frequently found in the ABCC8 and KCNJ11 genes coding for the two $\mathrm{K}_{\mathrm{ATP}}$-channel subunits SUR1 and Kir6.2 respectively
$(5,6)$. Whilst a recessive paternally inherited $\mathrm{K}_{\text {ATP }^{-}}$ channel mutation in combination with maternal loss of heterozygosity is associated with the focal histological type of $\mathrm{CHI}$, dominant or recessive $\mathrm{K}_{\mathrm{ATP}}$-channel mutations are associated with the diffuse CHI type (79). More rarely, dominant mutations in the (GCK) glucokinase, (GLUD1) glutamate dehydrogenase, (INSR) insulin receptor, (HNF4A) hepatocyte nuclear factor $4 \alpha$ genes and, most recently, in the promoter of the SLC16A1 (monocarboxylate transporter 1) gene have been found to cause $\mathrm{CHI}$ and similar syndromes featuring hyperinsulinaemic hypoglycaemia (10-14). 
Rare recessive mutations of the $H A D H$ (formerly $S C H A D)$ gene may also lead to this disease (15). For more than $50 \%$ of patients with $\mathrm{CHI}$ the genetic aetiology remains unknown $(16,17)$. This may in part be due to a lack of systematic genetic testing across the known genes involved in CHI.

GCK inactivating mutations cause GCK-maturityonset diabetes of the young (MODY), which is characterised by a right shift in the enzyme activity glucose dependency curve. By contrast, activating mutations lead to $\mathrm{CHI}$ with a left shift of the glucose dependency curve resulting in a lower threshold for glucose-stimulated insulin release (GSIR) $(18,19)$. The activating mutations described to date have been shown to map to a confined region of the enzyme, which has been termed the allosteric activator site and is remote to the substrate-binding site. Recently, polyubiquitin chains have been suggested to be endogenous ligands for this domain of the enzyme (20). A total of six mutations have been described in seven families with GCK-CHI $(10,18,21-24)$ indicating that the prevalence is low. However, GCK has not been investigated systematically in large series of $\mathrm{CHI}$ cases.

Unlike CHI caused by ABCC $8 / K C N J 11$ mutations, GCK-CHI is predicted to be responsive to $\mathrm{K}_{\mathrm{ATP}}$-channel openers such as diazoxide, as the $\mathrm{K}_{\mathrm{ATP}}$-channel is intact. However, there is evidence of at least one case where diazoxide treatment was unsuccessful, probably due to a functionally severe mutation (22). Here, we report a large series of patients with transient, persistent or recurrent $\mathrm{CHI}$, with a focus on cases with no $\mathrm{K}_{\mathrm{ATP}}{ }^{-}$ channel abnormalities $(n=108)$ from three European referral laboratories receiving patient DNA samples from several countries. The aim of this study was to estimate the prevalence and describe the phenotype of activating GCK mutations in children with CHI.

\section{Patients and methods}

\section{Subjects}

A consecutive pooled cohort of 201 children with an onset of CHI below 15 years of age and having genetic analysis performed in one out of our three genetic analysis centres were included in this study (Table 1). The patients came from different institutions in the UK, Denmark, Sweden, Norway, Portugal, Italy, Holland, Switzerland, Lithuania, Macedonia, Serbia, Turkey, Saudi Arabia, Malaysia, Singapore, Venezuela and Canada. Patient data were shared between the three referral centres to identify any duplicate samples.

A diagnosis of $\mathrm{CHI}$ was made at local institutions according to the definition of persistent, recurrent or transient hypoglycaemia greater than 1-week duration without any other explanation (e.g. maternal diabetes, intrauterine growth retardation, asphyxia, metabolic disease and medication) and a simultaneous
Table 1 Numbers and clinical characteristics of non-syndromic congenital hyperinsulinism $(\mathrm{CHI})$ patients screened for glucokinase (GCK) mutations in three referral centres.

\begin{tabular}{lcccc}
\hline $\begin{array}{l}\text { Cohort of CHI } \\
\text { patients }\end{array}$ & Denmark & Norway & UK & Total \\
\hline $\begin{array}{l}\text { All referred patients } \\
\text { (ABCC8/KCNJ11 }\end{array}$ & 141 & 26 & - & 167 \\
$\begin{array}{l}\text { positive or negative) } \\
A B C C 8 / K C N J 11\end{array}$ & 64 & 10 & 34 & 108 \\
negative cases & & & & \\
$\begin{array}{l}\text { screened for GCK } \\
\text { Medically responsive }\end{array}$ & 49 & 8 & 15 & 72 \\
$\begin{array}{l}\text { Pancreatic surgery } \\
\text { No data }\end{array}$ & 10 & 2 & 9 & 21 \\
\hline
\end{tabular}

inappropriately elevated p-insulin and/or p-C-peptide and suppressed free fatty acids and ketones. Blood glucose, p-insulin and C-peptide were analysed at the local institutions using variable methods.

The patients were categorised retrospectively as having medically non-responsive $\mathrm{CHI}$ (subjected to pancreatic surgery), or medically responsive CHI (diet and/or diazoxide \pm adjuvant therapy with chlorothiazide and nifedipine or octreotide). In patients where a GCK mutation was identified, further detailed clinical data were obtained from patient files. The exclusion criteria 'syndromic CHI' was defined as Beckwith-Wiedemann syndrome or other syndromes with gross anatomical morphological changes. Biochemical alterations suggesting CHI-GLUD1, CHI-HADH, CHI-INSR or CHISLC16A1 and mild dysmorphic facial features typical of CHI were not considered $(12,14,15,25-27)$. Informed consent was obtained according to national standards.

\section{Genetic screening}

In all UK patients, ABCC 8, KCNJ11 and GCK (GenBank NM_000352; NM_000525 and NM_000162 respectively) were sequenced directly on either an ABI3700 or ABI3100 capillary sequencer as described previously $(21,28)$. Sequences were compared with the published sequences using Mutation Surveyor v.3.0 (Biogene, Cambridge, UK). In the Danish centre, mutational screening of the three genes was performed by denaturing high-performance liquid chromatography (DHPLC) analysis of all exons and adjacent intron regions, with direct sequencing of abnormal chromatograms as described previously $(18,29)$. Sequences were analysed using SeqMan v. 7.2 from the DNASTAR software package (DNASTAR, Inc., WI, USA). In the Norwegian centre, screening was performed by direct sequencing on an ABI3730 capillary sequencer and sequences were analyzed using SeqScape Software v.2.1 (Applied Biosystems, Warrington, UK).

GCK analysis was performed in non-syndromic patients with a negative $A B C C 8$ and $K C N J 11$ mutational screening, or when one $\mathrm{K}_{\mathrm{ATP}}$-channel gene mutation could not explain the phenotype (e.g. a heterozygous 
$\mathrm{K}_{\mathrm{ATP}}$-channel gene mutation in $\mathrm{CHI}$ of uncertain histological type or a heterozygous mutation in $\mathrm{CHI}$ of diffuse type).

Prior to compiling prevalence data, patient databases were unblinded to identify duplicate samples referred to multiple testing centres. A total of six patients without $\mathrm{K}_{\mathrm{ATP}}$-channel mutations had been referred to the UK and Danish centres allowing a quality control check of the two mutation screening approaches in these centres. Out of these six cases, all had been successfully screened by direct sequencing in the UK. In the Danish centre one patient had been excluded due to DNA of poor quality; in the remaining five duplicate samples, the same DNA variations were identified by both the centres.

All GCK mutations were confirmed by PCR amplification of a fresh dilution of patient DNA. The frequency of novel mutations was examined in $>400$ normal chromosomes and co-segregation with $\mathrm{CHI}$ in parental DNA established. Parental relationships were confirmed by microsatellite analysis (details available on request).

\section{Biochemical characterisation of S64Y GCK}

Recombinant human islet wild-type (WT) enzyme and mutant S64Y GCK were generated and expressed in the form of glutathionyl-S-transferase fusion proteins as previously described (24). A structural analysis was performed using a homology model based on the WT-GCK crystal structure (30). Mathematical modelling was performed as described previously (19).

\section{Prevalence estimates}

GCK-CHI prevalences were estimated in two cohorts: i) relative to all non-syndromic children with $\mathrm{CHI}$ in the Danish-Norwegian international cohort including the five Danish-UK duplicate patients $(n=167)$; ii) relative to all non-syndromic $\mathrm{K}_{\mathrm{ATP}}$-channel negative children in the pooled Danish-Norwegian-UK cohort $(n=108)$ with subdivision into medically responsive $(n=72)$, and non-responsive, children $(n=21)$ (Table 1$)$.

\section{Results}

\section{Identification of GCK mutations}

A total of 167 non-syndromic children with a diagnosis of CHI were identified in the Danish-Norwegian international cohort. In the pooled Danish-Norwegian-UK cohort, 108 patients were negative for mutations in the $\mathrm{K}_{\mathrm{ATP}}$-channel genes ABCC8 and KCNJ11 and subjected to GCK mutation screening (Table 1).

GCK screening identified five patients with four different heterozygous mutations (c.191C > A, p.S64Y; c.194 C>T, p.T65I; c.295T>A, p.W99R and c.1367
C $>$ T, p.A456V). The details of three of these patients (T65I, W99R and A456V) have been reported previously $(18,21)$. A second unrelated proband with the W99R mutation was identified amongst the UK subjects. The sequencing of parental DNA established that the mutation had arisen de novo in the proband. A novel S64Y mutation was identified in a proband from the UK by two of the referral centres (UK and Denmark). This mutation was not present in $>400$ normal chromosomes and DNA sequencing and microsatellite analysis demonstrated that the mutation had arisen de novo in the proband. In our case series, two mutations arose de novo and vertical transmission was found in three families $(18,21)$.

\section{Clinical phenotype of GCK-CHI}

All five GCK-CHI patients had a diagnosis of hypoglycaemia from day 1 or within the neonatal period (Table 2). All the patients were males, born at term with a birth weight in the normal range (mean birth weight of $3382 \mathrm{~g}$ ). The mean birth weight in patients inheriting a mutation from an affected mother $(n=2)$ was $2765 \mathrm{~g}$ compared with $3793 \mathrm{~g}$ in those with unaffected mothers $(n=3)$. All were medically responsive, although patient 2 (W99R) had hypoglycaemia that was difficult to treat and required a maximal dose of diazoxide (up to $20 \mathrm{mg} / \mathrm{kg}$ per d) plus additional medication. This patient at 10 months of age had one documented episode of ketotic hypoglycaemia (blood glucose $1.2 \mathrm{mmol} / \mathrm{l}$ and hydroxybutyrate $1.10 \mathrm{mmol} / \mathrm{l}$ ) with raised p-lactate $(2.4 \mathrm{mmol} / \mathrm{l})$ and suppressed p-insulin and p-C-peptide. The investigation for other causes of hypoglycaemia was negative. The patient's affected asymptomatic father carrying the same mutation had a much milder phenotype and was only diagnosed following his son's genetic diagnosis at 33 years of age (lowest blood glucose $2.7 \mathrm{mmol} / \mathrm{l}$ ). Patient 3 carrying the same W99R mutation also had a milder phenotype, requiring lower doses of diazoxide $(8-9 \mathrm{mg} / \mathrm{kg}$ per d) without the need for additional medication. Patient $1(\mathrm{~A} 456 \mathrm{~V})$ had a period of 10 years without medication, but still required frequent meals to avoid hypoglycaemic symptoms. Both patients 1 (A456V) and 4 (T65I) received no medication throughout childhood, but experienced severe aggravation of their hypoglycaemic symptoms at 14 and 15 years of age respectively when treated with diazoxide. The other patients had a persistent need for diazoxide throughout childhood.

\section{Functional characterisation of the novel GCK S64Y mutation}

Purified mutant S64Y GCK showed a significant increase in affinity for glucose indicated by approximately a fivefold reduction in glucose $S_{0.5}(1.49 \pm 0.08$ and $7.39 \pm 0.05 \mathrm{mmol} / \mathrm{l}$ for $\mathrm{S} 64 \mathrm{Y}$ and WT respectively; Table 3$)$. The $\mathrm{km}$ for ATP was increased (1.07 \pm 0.05 
Table 2 Clinical characteristics of the five patients with glucokinase (GCK)-congenital hyperinsulinism (CHI).

\begin{tabular}{|c|c|c|c|c|c|}
\hline Patient number & 1 & 2 & 3 & 4 & 5 \\
\hline GCK mutation & A456V & W99R & W99R & T65I & S64Y \\
\hline Reference & (18) & (21) & Unpublished & $(21)$ & Unpublished \\
\hline Inheritance & Maternal & Paternal & De novo & Maternal & De novo \\
\hline Gender & Male & Male & Male & Male & Male \\
\hline Gestation (weeks) & Term & 37 & 39 & Term & 40 \\
\hline Birth weight (g) & 2400 & 3080 & 4000 & 3130 & 4300 \\
\hline $\begin{array}{l}\text { Age at first diagnosis of } \\
\text { hypoglycaemia }\end{array}$ & Day 1 & Day 1 & Day 1 & Neonatal & Day 1 \\
\hline Lowest blood glucose (mmol/l) & 2.3 & 1.2 & 2.1 & 2.0 & 2.0 \\
\hline \multicolumn{6}{|l|}{ Simultaneous } \\
\hline blood glucose $(\mathrm{mmol} / \mathrm{l})$ & 2.6 & 2.0 & 2.1 & 2.3 & 2.0 \\
\hline and p-Insulin (mU/l) & - & - & 28 & - & 12.1 \\
\hline /or p-Insulin (pmol/l) & 208 & 69 & - & 56 & - \\
\hline Clinical course & $\begin{array}{l}\text { Asymptomatic } \\
\text { after } 8 \text { months, } \\
\text { aggravation } \\
\text { with seizures. } \\
14 \text { years of age }\end{array}$ & $\begin{array}{l}\text { Persistent need of } \\
\text { medication } \\
\text { throughout } \\
\text { childhood }\end{array}$ & $\begin{array}{l}\text { Persistent need of } \\
\text { medication } \\
\text { throughout child- } \\
\text { hood. Presently } \\
18 \text { years of age }\end{array}$ & $\begin{array}{l}\text { Asymptomatic, } \\
\text { aggravation } \\
\text { with seizures. } \\
15 \text { years of age }\end{array}$ & $\begin{array}{l}\text { Persistent need of } \\
\text { medication. } \\
\text { Presently } 17 \\
\text { years of age }\end{array}$ \\
\hline Diazoxide responsive & Yes & Yes & Yes & Yes & Yes \\
\hline Diazoxide dose $(\mathrm{mg} / \mathrm{kg}$ per $\mathrm{d})$ & $0-12^{\mathrm{a}}$ & $20^{\mathrm{b}}$ & $8-9$ & $0-3.8$ & $10-12$ \\
\hline
\end{tabular}

an combination with chlorothiazide, change to octreotide long acting release in adulthood.

${ }^{b}$ In combination with chlorothiazide and nifedipine, also octreotide responsive.

and $0.64 \pm 0.04 \mathrm{mmol} / \mathrm{l}$ for $\mathrm{S} 64 \mathrm{Y}$ and WT respectively). The effective activation of mutant GCK is expressed by the increased activity index of $\sim 22$ compared with WT extrapolating to a marked enhancement of $\beta$-cell glucose usage (19). The structural modelling of S64Y showed that the mutated residue localises to the allosteric activator site. The physiological consequences of the kinetic characteristics of S64Y on GSIR, and therefore glucose homeostasis, were investigated using the published mathematical model that takes into account the impact of blood glucose levels on GCK expression of both alleles (19). Using this model, a predicted threshold of $1.4 \mathrm{mmol} / \mathrm{l}$ was obtained.

\section{Prevalence of activating GCK mutations}

In the largest study performed to date on non-syndromic CHI children without $\mathrm{K}_{\mathrm{ATP}}$-channel mutations, we have identified five patients with activating GCK mutations. The large sample size allows for the first time an estimation of the prevalence of GCK-CHI. In the DanishNorwegian international cohort, two GCK mutations were found among a total of 167 non-syndromic CHI patients, with or without $\mathrm{K}_{\mathrm{ATP}}$-channel mutations (Table 1). GCK analysis was performed in 101 out of these patients; that is, in all $\mathrm{K}_{\mathrm{ATP}}$-channel negative children with available DNA $(n=74)$ and in some children with $\mathrm{K}_{\mathrm{ATP}}$-channel mutations in search for additional genetic mutations $(n=27)$. The GCK mutations were only found in $\mathrm{K}_{\mathrm{ATP}}$-channel negative children. Assuming that no patients with a $\mathrm{K}_{\mathrm{ATP}}$-channel mutation also had a GCK mutation, the prevalence of GCK-CHI in all non-syndromic children with $\mathrm{CHI}$ is estimated to be $1.2 \%(2 / 167 ; 95 \%$ CI $0-2.8 \%)$.
In the $\mathrm{K}_{\mathrm{ATP}}$-channel negative pooled cohort of all three centres, the estimated prevalence of GCK mutations was $4.6 \%(5 / 108$; $95 \%$ CI $0.7-8.6 \%)$. Out of these patients, 72 were medically treated (including the five with GCK mutations) and 21 underwent pancreatic surgery (Table 1). Accordingly, the estimated prevalence of GCK-CHI in the medically treated group was $6.9 \%(5 / 72 ; 95 \%$ CI $1.1-12.8 \%)$, and zero in the group treated by surgery.

\section{Discussion}

\section{Activating GCK mutations}

Activating GCK mutations are rarely reported in CHI. Including this report, only seven mutations in nine families have been described, in contrast to over 200 inactivating GCK mutations causing the opposite phenotype, GCK-MODY $(10,18,21-24,31)$. In the present study, we have identified a seventh, naturally occurring activating GCK mutation (S64Y), and have functionally characterised the mutant enzyme. Our data

Table 3 Functional characterisation of the novel S64Y glucokinase (GCK) mutation.

\begin{tabular}{lll}
\hline Kinetic parameter & Wild-type GCK & S64Y GCK \\
\hline$K_{\text {cat }}\left(\mathrm{S}^{-1}\right)$ & $61.52 \pm 0.69$ & $54.03 \pm 0.52$ \\
Glucose $S_{0.5}(\mathrm{mmol} / \mathrm{l})$ & $7.39 \pm 0.05$ & $1.49 \pm 0.08$ \\
$\mathrm{nH}($ unitless) & $1.58 \pm 0.64$ & $1.33 \pm 0.13$ \\
ATP $K_{\mathrm{m}}(\mathrm{mmol} / \mathrm{l})$ & $0.64 \pm 0.04$ & $1.07 \pm 0.05$ \\
$\begin{array}{l}\text { Relative activity index } \\
\text { (unitless) }\end{array}$ & 1 & 22.4 \\
\hline
\end{tabular}

Data are mean \pm s.E.M. Results are based on the kinetic analysis of three independent expressions of wild-type and mutant GST-GCK. 
showed that this mutation, like other CHI-causing GCK mutations, maps to the allosteric activator site. Our kinetic characterisation demonstrated that the mutation was indeed activating and that the increased activity was driven by an increase in affinity for the substrate glucose (Table 3). A comparison with the previously reported and functionally characterised activating mutations demonstrated that S64Y is similar in potency to G68V and A456V (Fig. 1) (18, 24). The importance of performing functional studies is underscored by the limitations of database-based functional prediction in activating GCK mutations. Using the PolyPhen Database (http:/genetics.bwh.harvard.edu/ pph), the S64Y mutation was predicted to be damaging with a position-specific independent count (PSIC) difference score of 2.153. However, other functionally proven mutations (T65I, W99R and A456V) were predicted to be benign with PSIC scores of $0.187,0.192$ and 1.252 respectively.

With the addition of our novel mutation, the known naturally occurring activating GCK mutations mapping to the allosteric site are: S64Y, T65I, G68V, W99R, Y214C, V455M and A456V (10, 18, 21-24). In addition, the GCK-MODY V62M mutation has been shown to be kinetically activating in vitro. This paradox may be explained by the inability to bind regulatory proteins such as GCK regulatory protein GKRP and/or unidentified endogenous GCK activators (32). The allosteric area is involved in transforming GCK from the closed (active) to the super-open (nonactive) state of the enzyme, involving three intermediate stages $(30,33)$. Proposed natural ligands and activating mutations slow down the conformational changes between the intermediate stages from the closed to the super -open stage. To mimic the activating properties of GCK-CHI mutations, drugs have been designed to target the allosteric activating site in the treatment of T2DM $(30,34,35)$. These drugs have been shown to have their effect abolished by diazoxide in accordance with our finding that GCK-CHI was diazoxideresponsive (35).

\section{Phenotype}

There has been some debate whether all GCK-CHI patients are medically responsive. One historical patient with the Y214C genotype underwent subtotal pancreatectomy after an unsuccessful trial of diazoxide for 6 months at a dose of $2 \mathrm{mg} / \mathrm{kg}$ (22). In vitro, the Y214C mutation has very high activating properties with a relative activity index of $\sim 130$ compared with $\sim 30$ for A456V (Fig. 1). The patient was subjected to subtotal pancreatectomy, although the maximal diazoxide dose given was $5 \mathrm{mg} / \mathrm{kg}$ per $\mathrm{d}$, far from the maximally recommended dose of $20 \mathrm{mg} / \mathrm{kg}$ per d. It remains possible that the patient may have responded at higher doses and thereby avoided surgery. The treatment in this patient illustrates the problem of categorising GCK-CHI as severe or mild according to whether pancreatic surgery was performed (see below).

In GCK-MODY (caused by inactivating mutations) there is strong evidence that foetal growth is influenced by both the foetal and the maternal GCK genotypes (36). Affected offspring who have paternally inherited their mutation are on average $\sim 500 \mathrm{~g}$ lighter than those who have maternally inherited their mutation (36). The changes in birth weight are likely to reflect changes in foetal insulin secretion which in turn is influenced by the foetal genotype and indirectly by maternal hyperglycaemia. It is therefore likely that with activating GCK mutations, the opposite scenario exists; affected offspring who have paternally inherited their mutation would have increased birth weight whilst those who have maternally inherited their mutation would be predicted to have a birth weight within the normal range. Unfortunately, the small number of cases reported to date does not allow us to formally test this hypothesis.

Although all the patients in our study were diagnosed with hypoglycaemia in the neonatal period, several other GCK-CHI patients have been diagnosed at a much later age, even as late as adulthood $(10,18,21,23,24)$. The highly variable age of diagnosis is likely to be influenced by several factors including the functional severity of the mutations, the genetic background and delay in

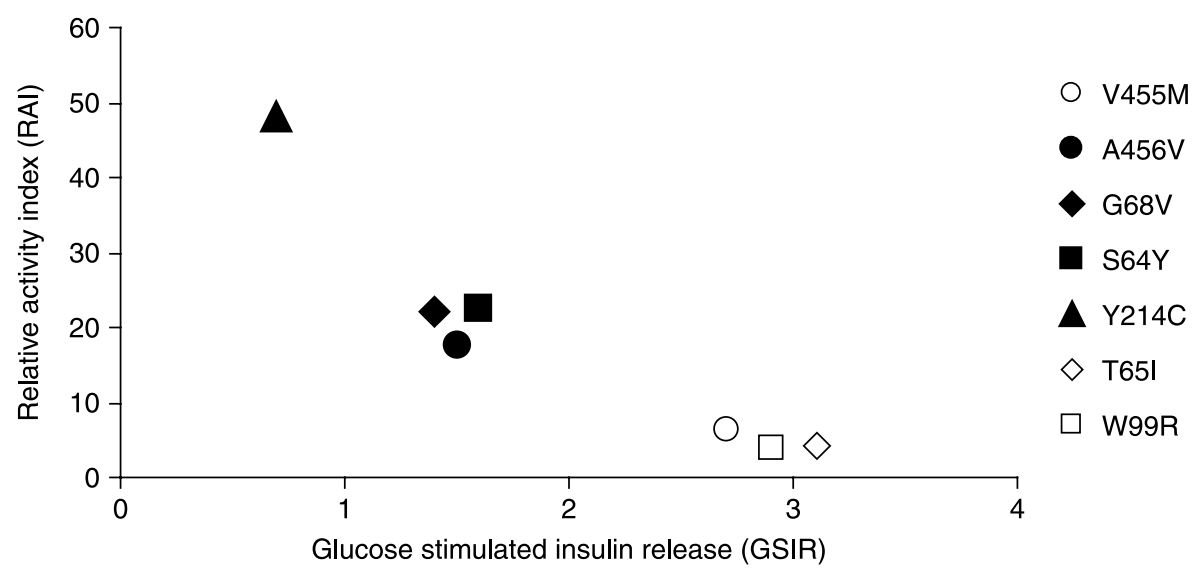

Figure 1 Graphical illustration of the functional characteristics of the seven naturally occurring mutations published to date. The graph illustrates the relationship between the relative activity index (RAI) of the mutant GCK enzyme and the predicted threshold for glucose-stimulated insulin release (GSIR). Kinetic data from original publications have been used to calculate RAI and the model used to calculate the threshold for GSIR is taken from Gloyn et al. (19). 
diagnosis. The phenotype of GCK-CHI may be highly variable even within families with the same GCK mutation $(10,18,21,23,24)$. In our study, the W99R GCK mutation was associated with both mild and more difficultly treated hypoglycaemia with occasional ketosis, although functional characterisation of this mutation has demonstrated only mild GCK activation (Fig. 1). Intermittent attacks of ketotic hypoglycaemia have been reported in two other diazoxide-treated $\mathrm{CHI}$ patients with unknown genetic aetiology (37). The coincidental occurrence of $\mathrm{CHI}$ and 'idiopathic' ketotic hypoglycaemia could explain the more severe phenotype of patient 2 and the two reported cases, although a rare side effect of diazoxide treatment cannot be excluded.

\section{Prevalence}

The prevalence of activating GCK mutations among children with $\mathrm{CHI}$ has hitherto not been systematically studied. The large number of patients included in the present study as a result of three international centres pooling cases allows a robust estimate of the prevalence of GCK-CHI. Among non-syndromic children with $\mathrm{CHI}$, only $1.2 \%$ had GCK alterations, whilst in nonsyndromic children with $\mathrm{CHI}$ without $\mathrm{K}_{\mathrm{ATP}}$-channel mutations, $4.6 \%$ had GCK-CHI. The frequency increased to $6.9 \%$ when only patients who were medically responsive were considered. GCK-CHI was not found in surgically treated patients, suggesting that medically non-responsive GCK-CHI is exceedingly rare if ever occurring with today's medication regime.

These estimates may have been influenced by the patient selection for genetic analysis. By recruiting children with $\mathrm{CHI}$ diagnosed within the first week, we may inadvertently have included a high proportion of children with transient neonatal $\mathrm{CHI}$, especially in those cases referred from Denmark. If a more restrictive definition had been employed, e.g. a minimum duration of 1 month, the prevalence estimate might have been higher, as the majority of patients with transient $\mathrm{CHI}$ do not have any of the known genetic aetiologies. However, in one of our patients (patient 4, T65I), the hypoglycaemia was asymptomatic and untreated in the neonatal period with a clinical relapse at 15 years of age. Mild or undetected hypoglycaemia in the neonatal period and a delayed onset of hypoglycaemic attacks up to adulthood have been seen in many other cases $(10,18,21,23,24)$. Accordingly, the exclusion of mild and transient neonatal cases could $a$ priori also lead to an underestimation of the true prevalence.

The prevalence estimates may also have been influenced by the inclusion of several patients from countries other than Denmark, UK and Norway. This could lead to a selection bias towards severely affected patients with an expected higher prevalence of $\mathrm{K}_{\mathrm{ATP}}{ }^{-}$ channel mutations. However, the majority of patients from other countries were not subjected to pancreatic surgery at the time of genetic analysis, and only few had a rapid genetic analysis for the prediction of focal versus diffuse disease (38). Moreover, the prevalence estimate of GCK-CHI in medically treated children without ABCC8/ KCNJ11 mutations could have been influenced by a different threshold for pancreatic surgery in different referral centres and over time. Finally, the sensitivity of the DHPLC method used by the Danish centre is estimated to be 95-100\% in GCK analysis (39), which may result in up to a $5 \%$ underestimation of the true prevalence. However, the comparable results from the five duplicate patients studied by both DHPLC and direct sequencing supported that the underestimation was low.

The medical CHI treatment of today includes a number of drugs and dose recommendations (17). Earlier recommendations of prompt subtotal pancreatectomy to reduce the risk of brain damage from hypoglycaemia are no longer supported for a number of reasons: i) focus ablation is sufficient to cure patients with focal disease (8), ii) some patients with diffuse CHI may be treated successfully by medication and eventually undergo clinical remission after months or even several years (40-42) and iii) subtotal pancreatectomy is complicated by an increased risk of subsequent diabetes and mild malabsorption (43). The switch towards a more conservative approach in diffuse $\mathrm{CHI}$ (if possible) and a rapid focal resection in focal $\mathrm{CHI}$ in many centres implies that a uniform definition of CHI as mild/ moderate or severe according to treatment modality may be questioned.

We propose that non-syndromic patients with medically responsive $\mathrm{CHI}$ who are negative for $\mathrm{K}_{\mathrm{ATP}}$ mutations should be considered for GCK genetic testing. Due to the low prevalence of GCK-CHI, the first genetic screening performed should in any case be of the $\mathrm{K}_{\mathrm{ATP}}$-channel genes $(A B C C 8 / K C N J 11)$ with the rare exception of a known GCK mutation in the family. If an activating GCK mutation is identified, the investigation of family members should be carried out to detect asymptomatic or mild symptomatic $\mathrm{CHI}$.

In conclusion, we have identified a novel S64Y GCK mutation and a second patient with the W99R mutation. We have performed the largest study to date of a pooled cohort of 108 patients from three international referral centres to assess the prevalence of GCK-CHI in subjects in whom $\mathrm{K}_{\mathrm{ATP}}$-channel mutations have been excluded. Our study suggests that activating GCK mutations are a rare cause of medically responsive $\mathrm{CHI}$ with an estimated prevalence of $\sim 7 \%$ in this group of patients. In non-syndromic children with $\mathrm{CHI}$, the overall prevalence of GCK-CHI was estimated to only $\sim 1 \%$.

\section{Acknowledgements}

The authors thank Sarah Flanagan for her assistance with compiling the clinical data on the UK patients with hypoglycaemia of infancy. This study was funded 
in Oxford by Diabetes UK and the University of Oxford John Fell Research Fund, in Denmark by the Danish Diabetes Association and the County of Funen, and in Norway by grants from Helse Vest and the Research Council of Norway. A L G is a Diabetes UK RD Lawrence Research Fellow. The authors have nothing to disclose.

\section{References}

1 Glaser B, Thornton PS, Herold K \& Stanley CA. Clinical and molecular heterogeneity of familial hyperinsulinism. Journal of Pediatrics 1998133 801-802.

2 Hussain K. Congenital hyperinsulinism. Seminars in Fetal and Neonatal Medicine 200510 369-376.

3 de Leon DD \& Stanley CA. Mechanisms of disease: advances in diagnosis and treatment of hyperinsulinism in neonates. Nature Clinical Practice Endocrinology and Metabolism 20073 57-68.

4 de Lonlay P, Simon A, Galmiche-Rolland L, Giurgea I, Verkarre V, Aigrain Y, Santiago-Ribeiro MJ, Polak M, Robert JJ, BellanneChantelot C, Brunelle F, Nihoul-Fekete C \& Jaubert F. Neonatal hyperinsulinism: clinicopathologic correlation. Human Pathology 200738 387-399.

5 Thomas PM, Cote GJ, Wohllk N, Haddad B, Mathew PM, Rabl W, Aguilar-Bryan L, Gagel RF \& Bryan J. Mutations in the sulfonylurea receptor gene in familial persistent hyperinsulinemic hypoglycemia of infancy. Science $1995 \mathbf{2 6 8} 426-429$.

6 Thomas P, Ye Y \& Lightner E. Mutation of the pancreatic islet inward rectifier Kir6.2 also leads to familial persistent hyperinsulinemic hypoglycemia of infancy. Human Molecular Genetics 19965 1809-1812.

7 Verkarre V, Fournet JC, de Lonlay P, Gross-Morand MS, Devillers M, Rahier J, Brunelle F, Robert JJ, Nihoul-Fekete C, Saudubray JM \& Junien C. Paternal mutation of the sulfonylurea receptor (SUR1) gene and maternal loss of $11 \mathrm{p} 15$ imprinted genes lead to persistent hyperinsulinism in focal adenomatous hyperplasia. Journal of Clinical Investigation 1998102 1286-1291.

8 de Lonlay-Debeney P, Poggi-Travert F, Fournet JC, Sempoux C, Vici CD, Brunelle F, Touati G, Rahier J, Junien C, Nihoul-Fekete C, Robert JJ \& Saudubray JM. Clinical features of 52 neonates with hyperinsulinism. New England Journal of Medicine $1999 \mathbf{3 4 0}$ 1169-1175.

9 Huopio H, Reimann F, Ashfield R, Komulainen J, Lenko HL, Rahier J, Vauhkonen I, Kere J, Laakso M, Ashcroft F \& Otonkoski T. Dominantly inherited hyperinsulinism caused by a mutation in the sulfonylurea receptor type 1. Journal of Clinical Investigation 2000 $106897-906$.

10 Glaser B, Kesavan P, Heyman M, Davis E, Cuesta A, Buchs A, Stanley CA, Thornton PS, Permutt MA, Matschinsky FM \& Herold KC. Familial hyperinsulinism caused by an activating glucokinase mutation. New England Journal of Medicine 1998338 226-230.

11 Stanley CA, Lieu YK, Hsu BY, Burlina AB, Greenberg CR, Hopwood NJ, Perlman K, Rich BH, Zammarchi E \& Poncz M. Hyperinsulinism and hyperammonemia in infants with regulatory mutations of the glutamate dehydrogenase gene. New England Journal of Medicine 1998338 1352-1357.

12 Hojlund K, Hansen T, Lajer M, Henriksen JE, Levin K, Lindholm J, Pedersen $O$ \& Beck-Nielsen $H$. A novel syndrome of autosomaldominant hyperinsulinemic hypoglycemia linked to a mutation in the human insulin receptor gene. Diabetes 200453 1592-1598.

13 Pearson ER, Boj SF, Steele AM, Barrett T, Stals K, Shield JP, Ellard S, Ferrer J \& Hattersley AT. Macrosomia and hyperinsulinaemic hypoglycaemia in patients with heterozygous mutations in the HNF4A gene. Public Library of Science Medicine 2007 e118 $760-769$.

14 Otonkoski T, Jiao H, Kaminen-Ahola N, Tapia-Paez I, Ullah MS, Parton LE, Schuit F, Quintens R, Sipila I, Mayatepek E, Meissner T,
Halestrap AP, Rutter GA \& Kere J. Physical exercise-induced hypoglycemia caused by failed silencing of monocarboxylate transporter 1 in pancreatic beta cells. American Journal of Human Genetics 200781 467-474.

15 Clayton PT, Eaton S, Aynsley-Green A, Edginton M, Hussain K, Krywawych S, Datta V, Malingre HE, Berger R \& van den Berg I. Hyperinsulinism in short-chain L-3-hydroxyacyl-CoA dehydrogenase deficiency reveals the importance of beta-oxidation in insulin secretion. Journal of Clinical Investigation $2001 \mathbf{1 0 8}$ 457-465.

16 Tornovsky S, Crane A, Cosgrove KE, Hussain K, Lavie J, Heyman M, Nesher Y, Kuchinski N, Ben-Shushan E, Shatz O, Nahari E, Potikha T, Zangen D, Tenenbaum-Rakover Y, de Vries L, Argente J, Gracia R, Landau H, Eliakim A, Lindley K, Dunne MJ, Aguilar-Bryan L \& Glaser B. Hyperinsulinism of infancy: novel ABCC 8 and KCNJ11 mutations and evidence for additional locus heterogeneity. Journal of Clinical Endocrinology and Metabolism $2004896224-6234$.

17 Hussain K. Diagnosis and management of hyperinsulinaemic hypoglycaemia of infancy. Hormone Research $2008692-13$.

18 Christesen HB, Jacobsen BB, Odili S, Buettger C, Cuesta-Munoz A, Hansen T, Brusgaard K, Massa O, Magnuson MA, Shiota C, Matschinsky FM \& Barbetti F. The second activating glucokinase mutation (A456V): implications for glucose homeostasis and diabetes therapy. Diabetes 200251 1240-1246.

19 Gloyn AL, Odili S, Buettger C, Njolstad PR, Shiota C, Magnuson MA \& Matschinsky FM. Glucokinase and the regulation of blood sugar: a mathematical model predicts the threshold for glucose stimulated insulin release for GCK gene mutations that cause hyper- and hypoglycaemia. In Glucokinase and Glycemic Disease: From Basics to Novel Therapeutics, edn 1, Ch 6, pp 92-109. Eds MA Magnuson \& FM Matschinsky Basel: Karger, 2004.

20 Bjorkhaug L, Molnes J, Sovik O, Njolstad PR \& Flatmark T. Allosteric activation of human glucokinase by free polyubiquitin chains and its ubiquitin-dependent cotranslational proteasomal degradation. Journal of Biological Chemistry 2007282 2275722764 .

21 Gloyn AL, Noordam K, Willemsen MA, Ellard S, Lam WW, Campbell IW, Midgley P, Shiota C, Buettger C, Magnuson MA, Matschinsky FM \& Hattersley AT. Insights into the biochemical and genetic basis of glucokinase activation from naturally occurring hypoglycemia mutations. Diabetes $2003 \mathbf{5 2}$ 2433-2440.

22 Cuesta-Munoz AL, Huopio H, Otonkoski T, Gomez-Zumaquero JM, Nanto-Salonen K, Rahier J, Lopez-Enriquez S, Garcia-Gimeno MA, Sanz P, Soriguer FC \& Laakso M. Severe persistent hyperinsulinemic hypoglycemia due to a de novo glucokinase mutation. Diabetes $2004532164-2168$.

23 Dullaart RP, Hoogenberg K, Rouwe CW \& Stulp BK. Family with autosomal dominant hyperinsulinism associated with A456V mutation in the glucokinase gene. Journal of Internal Medicine 2004255 143-145.

24 Wabitsch M, Lahr G, Van de Bunt M, Marchant C, Lindner M, von Puttkamer J, Fenneberg A, Debatin KM, Klein R, Ellard S, Clark A \& Gloyn AL. Heterogeneity in disease severity in a family with a novel G68V GCK activating mutation causing persistent hyperinsulinaemic hypoglycaemia of infancy. Diabetic Medicine 200724 1393-1399.

25 Stanley CA, Lieu YK, Hsu BY, Burlina AB, Greenberg CR, Hopwood NJ, Perlman K, Rich BH, Zammarchi E \& Poncz M. Hyperinsulinism and hyperammonemia in infants with regulatory mutations of the glutamate dehydrogenase gene. New England Journal of Medicine 1998338 1352-1357.

26 de Lonlay P, Cormier-Daire V, Amiel J, Touati G, Goldenberg A, Fournet JC, Brunelle F, Nihoul-Fekete C, Rahier J, Junien C, Robert JJ \& Saudubray JM. Facial appearance in persistent hyperinsulinemic hypoglycemia. American Journal of Medical Genetics 2002111 130-133. 
27 Molven A, Matre GE, Duran M, Wanders RJ, Rishaug U, Njolstad PR, Jellum E \& Sovik O. Familial hyperinsulinemic hypoglycemia caused by a defect in the SCHAD enzyme of mitochondrial fatty acid oxidation. Diabetes 200453 221-227.

28 Flanagan SE, Patch AM, Mackay DJ, Edghill EL, Gloyn AL, Robinson D, Shield JP, Temple K, Ellard S \& Hattersley AT. Mutations in ATP-sensitive $\mathrm{K}+$ channel genes cause transient neonatal diabetes and permanent diabetes in childhood or adulthood. Diabetes 200756 1930-1937.

29 Hussain K, Bryan J, Christesen HT, Brusgaard K \& AguilarBryan L. Serum glucagon counterregulatory hormonal response to hypoglycemia is blunted in congenital hyperinsulinism. Diabetes $2005 \mathbf{5 4} 2946-2951$.

30 Kamata K, Mitsuya M, Nishimura T, Eiki J \& Nagata Y. Structural basis for allosteric regulation of the monomeric allosteric enzyme human glucokinase. Structure $20042429-438$.

31 Gloyn AL. Glucokinase (GCK) mutations in hyper- and hypoglycemia: maturity-onset diabetes of the young, permanent neonatal diabetes, and hyperinsulinemia of infancy. Human Mutation 2003 22 353-362.

32 Gloyn AL, Odili S, Zelent D, Buettger C, Castleden H, Steele AM, Stride A, Shiota C, Magnuson MA, Lorini R, d'Annunzio G, Stanley CA, Kwagh J, van Schaftingen E, Veiga-da-Cunha M, Barbetti F, Dunten P, Han Y, Grimsby J, Taub R, Ellard S, Hattersley AT \& Matschinsky FM. Insights into the structure and regulation of glucokinase from a novel mutation (V62M), which causes maturity-onset diabetes of the young. Journal of Biological Chemistry 2005280 14105-14113.

33 Zhang J, Li C, Chen K, Zhu W, Shen X \& Jiang H. Conformational transition pathway in the allosteric process of human glucokinase. PNAS 2006103 13368-13373.

34 Grimsby J, Sarabu R, Corbett WL, Haynes NE, Bizzarro FT, Coffey JW, Guertin KR, Hilliard DW, Kester RF, Mahaney PE, Marcus L, Qi L, Spence CL, Tengi J, Magnuson MA, Chu CA, Dvorozniak MT, Matschinsky FM \& Grippo JF. Allosteric activators of glucokinase: potential role in diabetes therapy. Science 2003 $301370-373$.
35 Johnson D, Shepherd RM, Gill D, Gorman T, Smith DM \& Dunne MJ. Glucose-dependent modulation of insulin secretion and intracellular calcium ions by GKA50, a glucokinase activator. Diabetes 200756 1694-1702.

36 Hattersley AT, Beards F, Ballantyne E, Appleton M, Harvey R \& Ellard S. Mutations in the glucokinase gene of the fetus result in reduced birth weight. Nature Genetics 199819 268-270.

37 Hussain K. Ketotic hypoglycaemia in children with diazoxide responsive hyperinsulinism of infancy. European Journal of Pediatrics $2005164387-390$.

38 Christesen HB, Brusgaard K, Alm J, Sjoblad S, Hussain K, Fenger C, Rasmussen L, Hovendal C, Otonkoski T \& Jacobsen BB. Rapid genetic analysis in congenital hyperinsulinism. Hormone Research 200767 184-188.

39 Boutin P, Vasseur F, Samson C, Wahl C \& Froguel P. Routine mutation screening of HNF- $1 \alpha$ and GCK genes in MODY diagnosis: how effective are the techniques of DHPLC and direct sequencing used in combination? Diabetologia 200144 775-778.

40 Christesen HB, Feilberg-Jorgensen N \& Jacobsen BB. Pancreatic beta-cell stimulation tests in transient and persistent congenital hyperinsulinism. Acta Paediatrica 200190 1116-1120.

41 Kassem SA, Ariel I, Thornton PS, Scheimberg I \& Glaser B. Betacell proliferation and apoptosis in the developing normal human pancreas and in hyperinsulinism of infancy. Diabetes $2000 \mathbf{4 9}$ $1325-1333$.

42 Mazor-Aronovitch K, Gillis D, Lobel D, Hirsch HJ, Pinhas-Hamiel O, Modan-Moses D, Glaser B \& Landau H. Long-term neurodevelopmental outcome in conservatively treated congenital hyperinsulinism. European Journal of Endocrinology 2007157 491-497.

43 Al-Nassar S, Sakati N, al-Ashwal A \& Bin-Abbas B. Persistent hyperinsulinaemic hypoglycaemia of infancy in 43 children: longterm clinical and surgical follow-up. Asian Journal of Surgery 2006 29 207-211.

Received 18 April 2008

Accepted 22 April 2008 